\title{
Evaluasi Prosedur Penyusunan Anggaran dan Penetapan Anggaran
}

\author{
Eni Kaharti \\ Program Studi Manajemen \\ STIE Putra Bangsa Kebumen \\ enikarahajeng198.stiepb@gmail.com
}

\begin{abstract}
This research aimed to identify the roles of budget as a means of planning, controlling, and decision making at a hotel company, namely VSSB. This research evaluated budgeting process using the guidelines of Anthony and Govindarajan (2011) and Nafarin (2013). Budgetary control was evaluated in two ways, namely: (1) evaluation of budget implementation, (2) evaluation of budget achievement. The evaluation of calculating cost of room sold is a basis for determining a selling price by giving discounts. Cost classification is required in deciding budget management (Supriyono, 1989). Costs are classified according to their purpose.

The results of this research indicated that the procedure for making budget in VSSB 2018 was normatively in compliance with budgeting procedure. GOP generated by VSSB could be classified as low budget (below 40\%). In Seminyak Bali, VSSB was regarded as a leader in the hotel business based on hotel competitor report. The simulation of the basic room costs in VSSB was already proper so that giving discounts would not result in loss.
\end{abstract}

Keywords: budget, planning, controlling, decision making, cost classification, BEP analysis and CVP analysis

\section{PENDAHULUAN}

Secara umum tujuan dari mendirikan sebuah perusahaan adalah mendapatkan keuntungan/laba yang optimal. Keuntungan yang optimal akan diperoleh apabila perusahaan dikelola dengan baik dan benar. Salah satu pengelolaan perusahaan yang baik dan benar yaitu perusahaan dikelola dengan pengendalian manajemen yang tepat sesuai dengan sasaran/ tujuan.

Pembuatan anggaran sangat penting dilakukan olehsetiap perusahaan, baik perusahaan yang berskala besar maupun kecil, organisasi bisnis ataupun nirlaba. Anggaran berperan penting dalam rangka sarana untuk mencapai tujuan organisasi/perusahaan yaitu mendapatkan keuntungan atas perencanaan dan pengendalian manajemen. Hansen dan Mowen (1999).

Menurut Hansen dan Mowen (1999) kegiatan perencanaan dan pengendalian merupakan kegiatan yang berkaitan erat. Dalam perencanaan akan ditetapkan langkah-langkah untuk mewujudkan tujuan organisasi, sedangkan kegiatan pengendalian merupakan kegiatan review kinerja yaitu dengan evaluasi perencanaan dibandingkan dengan realisasi

Terdapat hubungan yang erat antara anggaran dan rencana strategis. Anggaran merupakan komponen utama kegiatan perencanaan, yang meliputi perencanaan keuangan pada masa depan, tujuan dan tindakan yang tepat untuk mencapai tujuan organisasi/ perusahaan.

Kegiatan perencanaan dan pengendalian anggaran perlu dievaluasi untuk mengetahui sejauhmana efektivitas dalam pencapaiannya. Pentingnya keputusan yang tepat dalam penentuan pendapatan dari kegiatan revenue center harus dilakukan dengan benar dalam rangka memenangkan persaingan bisnis perhotelan.

\section{TINJAUAN PUSTAKA \\ Pengertian Anggaran}

Dalam pengelolaan perusahaan manajemen menetapkan tujuan dan sasaran yang tertuang dalam visi dan misi perusahaan. Upaya pencapaian tujuan dan sasaran perusahaan yaitu dengan menyusun rencana kegiatan operasional dengan satuan moneter yang secara umum dituangkan dalam bentuk anggaran. 
Menurut Nafarin (2004), pengertian anggaran adalah anggaran merupakan rencana tertulis mengenai kegiatan suatu organisasi yang dinyatakan secara kuantitatif untuk jangka waktu tertentu dan umumnya dinyatakan dalam satuan uang, tetapi dapat juga dinyatakan dalam satuan barang maupun jasa.

Menurut Anthony dan Govindarajan (2011) anggaran merupakan sebuah rencana keuangan, biasanya mencakup periode satu tahun dan merupakan alat-alat untuk perencanaan jangka pendek dan pengendalian dalam organisasi.

Pada batasan anggaran menurut pakar-pakar diatas dapat disimpulkan bahawa didalam anggaran terdapat perencanaan kegiatan dalam satuan uang,barang maupun jasa untuk jangka waktu tertentu yang menjadi alat pengendalian organisasi. Dalam hal ini dapat ditunjukkan bahwa anggaran dapat digunakan sebagai salah satu alat pengendalian perusahaan dengan dasar perencanaan keuangan.

\section{Prosedur Penyusunan Anggaran}

Menurut Antony dan Govindarajan (2011) prosedur penyusunan anggaran terdiri dari 7 tahap, yaitu: (1) Organisasi, (2) Penerbitan pedoman, (3) Usulan awal anggaran, (4) Negosiasi, (5) Tinjauan dan Persetujuan, (6) Revisi Anggaran, (7) Anggaran Kontinjensi.

\section{Pentingnya Penggolongan Biaya}

Menurut Supriyono (1989) tujuan dari penggolongan biaya yaitu antara lain sebagai perencanaan, pengambilan keputusan, pengendalian dan pelaporan pihak eksternal. Supriyono, 2011:32 dalam Maylisa dan Budi, 2013 menyatakan bahwa penggolongan biaya yaitu proses pengelompokan atas seluruh elemen yang ada ke dalam golongan-golongan tertentu, yang lebih ringkas untuk dapat memberikan informasi biaya yang lebih berarti.

Dalam kegiatan penggolongan biaya tergantung untuk apa biaya tersebut digolongkan, untuk tujuan yang berbeda diperlukan cara penggolongan biaya yang berbeda pula dengan kata lain bahwa tidak ada satu cara penggolongan biaya yang dapat dipakai untuk semua tujuan menyajikan informasi biaya.

\section{Analisis Biaya-Volume-Laba (CVP : cost volume profit) dan Analisis Titik Impas (BEP: Break Event Point)}

Dalam penyusunan anggaran analisis biaya volume laba digunakan sebagai alat perencanaan laba jangka pendek. Analisis biaya-volume-laba juga dasar dalam berbagai keputusan manajemen terkait penentuan harga jual produk, volume atau tingkat kegiatan, biaya variabel per unit, total biaya tetap dan komposisi komposisi produk atau jasa yang dijual.

Rumus impas juga digunakan untuk menentukan perencanaan laba yang diharapkan. Rumus ini dapat juga digunakan unuk menyusun anggaran dengan cara menentukan tingkat penjualan.

Menurut Supriyono (1989:141) pengertian impas adalah keadaan suatu perusahaan yang pendapatan penjualannya sama dengan total biayanya, atau besarnya laba kontribusi sama dengan total biaya tetap, dengan kata lain perusahaan tidak memperoleh laba tetapi juga tidak rugi, laba $=0$

$$
\begin{aligned}
& \text { Rumus : } \\
& \text { Penjualan }=\text { Biaya }+ \text { Laba, } \\
& \text { px }=b x+a+i
\end{aligned}
$$

\section{METODE}

Penelitian ini menggunakan metodologi kualitatif. Menurut Cooper dan Schindler (2006) penelitian kualitatif terdiri dari suatu rangkaian tehnik interpretasi yang akan menjelaskan, mentransformasikan, menterjemahkan dan menjelaskan makna, bukan frekuensi dari suatu kejadian dalam dunia sosial yang kurang lebih terjadi secara alami. Penelitian kualitatif ditujukan untuk mendapatkan pemahaman yang mendalam akan suatu situasinya. Lokasi penelitian Jalan Cendrawasih No 27x, Pettitenget Kerobokan Kelod, Kuta Utara, Kabupaten Badung, Bali.

Sampel yang digunakan dalam penelitian ini adalah General Manager, dan para Head of departement VSSB. Metode pengambilan sampel adalah purposive sampling, adalah memilih responden dengan tujuan khusus. Data yang digunakan dalam penelitian ini data primer dan data sekunder. Sumber data primer yaitu, profile VSSB dan informasi yang diperoleh secara langsung dari responden. Sumber data sekunder 
diperoleh dari budget dan realisasi tahun 2017 dan tahun 2018, Standar Operating Prosedur (SOP), formulir, dokumen kegiatan dan foto-foto kegiatan.

Dalam hal pengumpulan data dengan cara melakukan wawancara pada responden yang telah ditentukan dan observasi langsung ke lapangan, yaitu dengan teknik wawancara mendalam dan teknik observasi. Untuk menganalisis data kuantitatif menggunakan tiga prosedur, yaitu reduksi data, penyajian data, dan penarikan kesimpulan.

\section{HASIL DAN PEMBAHASAN}

\section{Evaluasi Prosedur Penyusunan Anggaran}

Dalam proses penyusunan anggaran VSSB mengalami perubahan mekanisme prosedur. Yaitu periode tahun 2017 dan tahun 2018.

\section{Tahap-tahap penyusunan anggaran menurut Anthony dan Govindarajan (2011)}

Berdasar hasil komparasi prosedur penyusunan anggaran antara prosedur yang dilaksanakan oleh MK dan menurut Anthony dan Govindarajan (2011), pada tahun 2015 MK sebagian tahapan sesuai prosedur yang tepat dalam proses penyusunan anggaran akan tetapi sebagian yang lain tidak seasuai posedur. Pada tahun 2016 seluruh prosedur yang dilaksanakan oleh MK sesuai dengan prosedur menurut Antony dan Govindarajan (2011). Sedangkan pada tahapn penyusunan anggaran menurut Nafarin maka pada proses penyusunan anggaran MK tahun 2015 dan tahun 2016 telah sesuai.
Tabel 1.

Komparasi Prosedur Penyusunan anggaran Menurut Anthony dan Govindarajan (2011) dan Penyusunan Anggaran Meotel Kebumen Tahun 2015 dan 2016

\begin{tabular}{|c|c|c|c|c|c|}
\hline \multirow[t]{3}{*}{ No } & \multirow{3}{*}{$\begin{array}{l}\text { Prosedur } \\
\text { penyusunan } \\
\text { Anggaran } \\
\text { Antony dan } \\
\text { Govindarajan } \\
(2011)\end{array}$} & \multicolumn{4}{|c|}{$\begin{array}{l}\text { Prosedur penyusunan } \\
\text { Anggaran } \\
\text { Meotel Kebumen }\end{array}$} \\
\hline & & \multicolumn{2}{|c|}{ Tahun 2015} & \multicolumn{2}{|c|}{ Tahun 2016} \\
\hline & & Ada & $\begin{array}{l}\text { Tidak } \\
\text { Ada }\end{array}$ & Ada & $\begin{array}{l}\text { Tidak } \\
\text { Ada }\end{array}$ \\
\hline 1 & Organisasi & $\sqrt{ }$ & & $\sqrt{ }$ & \\
\hline 2 & $\begin{array}{l}\text { Penerbitan } \\
\text { pedoman }\end{array}$ & $\sqrt{ }$ & & $\sqrt{ }$ & \\
\hline 3 & $\begin{array}{l}\text { Usulan awal } \\
\text { anggaran }\end{array}$ & $\sqrt{ }$ & & $\sqrt{ }$ & \\
\hline 4 & Negosiasi & & $\sqrt{ }$ & $\sqrt{ }$ & \\
\hline 5 & $\begin{array}{l}\text { Tinjauan dan } \\
\text { Persetujuan }\end{array}$ & $\sqrt{ }$ & & $\sqrt{ }$ & \\
\hline 6 & $\begin{array}{l}\text { Revisi } \\
\text { Anggaran }\end{array}$ & & $\sqrt{ }$ & $\sqrt{ }$ & \\
\hline 7 & $\begin{array}{l}\text { Anggaran } \\
\text { Kontinjensi }\end{array}$ & & $\sqrt{ }$ & $\sqrt{ }$ & \\
\hline
\end{tabular}


Tahap-tahap penyusunan anggaran menurut Nafarin (2013)

\section{Tabel 2}

Komparasi Prosedur Penyusunan Anggaran menurut Nafarin (2013) dan Prosedur

Penyusunan Anggaran Meotel Kebumen Tahun 2015 dan 2016

\begin{tabular}{|c|c|c|c|c|c|}
\hline \multirow[t]{3}{*}{ No } & \multirow{3}{*}{$\begin{array}{l}\text { Prosedur } \\
\text { penyusunan } \\
\text { Anggaran } \\
\text { Nafarin } \\
\text { (2013) }\end{array}$} & \multicolumn{4}{|c|}{$\begin{array}{l}\text { Prosedur penyusunan } \\
\text { AnggaranVSSB }\end{array}$} \\
\hline & & \multicolumn{2}{|c|}{ Tahun 2017} & \multicolumn{2}{|c|}{ Tahun 2018} \\
\hline & & Ada & $\begin{array}{l}\text { Tidak } \\
\text { Ada }\end{array}$ & Ada & $\begin{array}{l}\text { Tidak } \\
\text { Ada }\end{array}$ \\
\hline 1 & $\begin{array}{l}\text { Penentuan } \\
\text { Pedoman } \\
\text { Anggaran }\end{array}$ & $\sqrt{ }$ & & $\sqrt{ }$ & \\
\hline 2 & $\begin{array}{l}\text { Persiapan } \\
\text { Anggaran }\end{array}$ & $\sqrt{ }$ & & $\sqrt{ }$ & \\
\hline 3 & $\begin{array}{l}\text { Penentuan } \\
\text { Anggaran }\end{array}$ & $\sqrt{ }$ & & $\sqrt{ }$ & \\
\hline 4 & $\begin{array}{l}\text { Pelaksanaan } \\
\text { Anggaran }\end{array}$ & $\sqrt{ }$ & & $\sqrt{ }$ & \\
\hline
\end{tabular}

Evaluasi Pengendalian

Anggaran Pendapatan (Revenue)

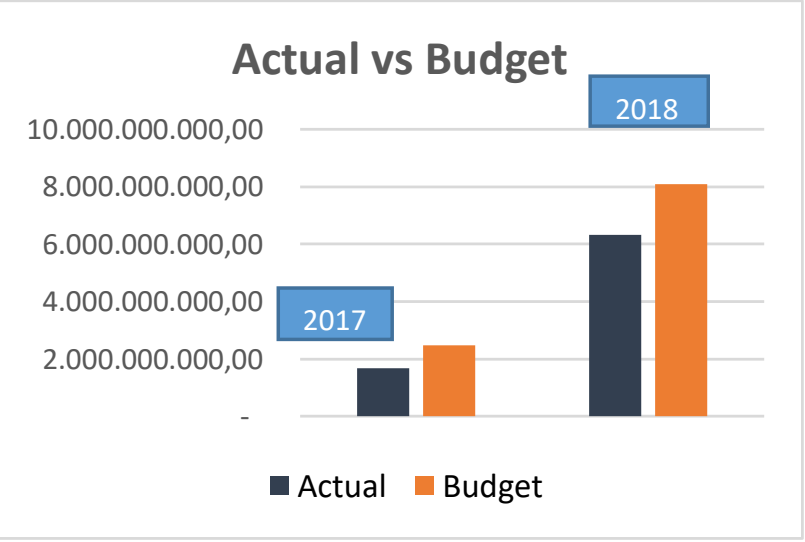

Tahun 2018 mencapai actual revenue sebesar $78,11 \%$ dari revenue budget yang telah ditetapkan. Pencapaian ini lebih tinggi dari pencapaian tahun 2017, naik sekitar 10,70\%. Tahun kedua beroperasinya VSSB menggunakan acuan anggaran yang ditetapkan 2017 dengan belajar dari pengalaman tahun sebelumnya.
Evaluasi Anggaran dan Realisasi Biaya Biaya (Expenses)

\section{Actual vs Budget}

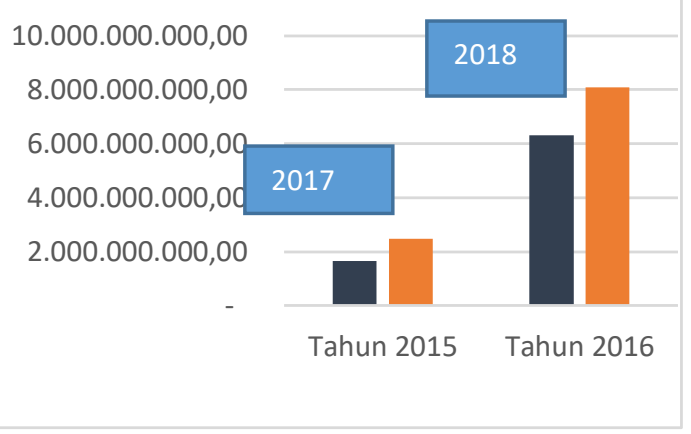

Dan tahun 2018 actual expense terserap sebesar 99,71\% dari expense budget. Hampir seluruh expense budget terserap di tahun 2018, hal ini menunjukkan anggaran pembiayaan dilakukan dengan lebih cermat.

\section{Hasil GOP (Gross Operating Product)}

Pada tahun 2017 VSSB GOP rata-rata sebesar 27,44\% sedangkan penetapan anggaran GOP adalah 40,10 \%. Pada tahun 2018, GOP mencapai 26,78\% dengan anggaran GOP 40,97\%. Dari penilaian pencapaian GOP, VSSB pada tahun 2017 dan tahun 2018 termasuk lower budget.

Teori Schimidgal (Agustine Fenny, 2007, dalam Lestari dan Sulindawati, 2013) menjelaskan bahwa penilaian bisnis hotel dalam skala GOP (gross operating product) adalah sebagai berikut:

a.GOP < 40\%, dari sales budget artinya mengalami lower budget

b.GOP $40 \%$ - $60 \%$ dari sales budget artinya mengalami normal budget

c.GOP > 60\% dari sales budget artinya mengalami over budget

Simulasi Perencanaan Anggaran Laba dan Pendapatan Dengan Analisis Biaya-VolumeLaba

\section{Menghitung BEP dengan menggunakan marjin kontribusi \\ Jika \\ biaya tetap per bulan $\quad$ Rp120.000.000,00 \\ Biaya variabel per kamar $\quad \mathrm{Rp} \quad 280.000,00$ \\ Harga jual per kamar $\quad \mathrm{Rp} \quad 400,000,00$}


Maka untuk menghitung titik impas adalah sebagai berikut.

Rumus = Harga jual - Biaya variabel per kamar $=\mathrm{Rp} 400.000,00-\mathrm{Rp} 280.000,00$

$=\mathrm{Rp} 120.000,00$

Unit yang terjual pada titik impas

$=(\operatorname{Rp} 120.000 .000+$ target laba operasi $(\operatorname{Rp} 0))$ : Rp 120.000

$=1000$ unit

VSSB memiliki kapasitas 72 kamar, bila VSSB terpenuhi 1000 kamar per bulan, berarti pada bulan tersebut mencapai tingkat hunian/occupancy sebesar: 72 kamar x 30 hari $=2160$ kamar, 1000 kamar $/ 2160$ kamar $=46 \%$. Jadi dengan 1000 kamar terpenuhi MK mencapai occupancy $46 \%$

\section{Menghitung BEP dengan menggunakan rasio margin kontribusi}

$$
\begin{aligned}
\text { Penjualan pada titik impas } & =\frac{\text { biaya tetap }}{\text { margin kontribusi }} \\
& =\frac{120.000}{400.000} \\
& =30 \%
\end{aligned}
$$

\section{Analisis CVP (Biaya-Volume-Laba)}

Jika VAAB menginginkan laba operasi sebesar Rp 120.000

$$
\begin{aligned}
\text { Penjualan titik impas } & =\frac{\text { biaya tetap }+ \text { target laba }}{\text { margin kontribusi }} \\
& =\frac{120.000+120.000}{400.000} \\
& =2.000 \mathrm{kamar}
\end{aligned}
$$

Bila VSSB terpenuhi 2000 kamar per bulan, berarti pada bulan tersebut mencapai tingkat hunian/occupancy sebesar:

72 kamar x 30 hari =2160 kamar, 2000 kamar / 2160 kamar $=93 \%$

Jadi dengan 2000 kamar terpenuhi VSSB mencapai occupancy $93 \%$.

Pendapatan yang harus diperoleh untuk mendapatkan laba Rp 120,000,000,00

\section{Penjualan pada titik impas $=($ Biaya tetap + Target laba) / Margin Kontribusi}

Rasio Margin kontribusi

$=\operatorname{Rp} 120,000,00: \operatorname{Rp} 400.000,00$

$=30 \%$
Penjualan titik impas

$=(\mathrm{Rp} 120.000 .000,00+\mathrm{Rp} 120,000,000,00): 30 \%$

$=\mathrm{Rp} 480.000,00$

Dari hasil simulasi bila VSSB ingin mencapai titik impas dengan marjin kontribusi harus mencapai penjualan sebanyak 1000 unit kamar per bulan dengan tingkat hunian /occupancy $46 \%$ dan jumlah pendapatan Rp400.000.000,00 per bulan. Jika MK ingin mendapatkan laba operasional sebesar Rp120,000,000,00 maka harus menjual 2000 unit kamar, dengan tingkat hunian/occupancy $93 \%$ dan pendapatan sebesar Rp 800,000,000,00

\section{PENUTUP}

\section{Kesimpulan}

Dari hasil uraian pembahasan hasil penelitian dapat ditarik simpulan sebagai berikut.

1. Hasil penelitian ini menunjukkan bahwa prosedur penyusunan anggaran di VSSB tahun 2018 sudah sesuai dengan prosedur penyusunan anggaran secara normatif.

2. Hasil evaluasi anggaran dan realisasi pendapatan tahun 2017 dan tahun 2018 maka terlihat pada tahun 2017 pencapaian actual revenue sebesar $78,11 \%$ dari revenue budget yang telah ditetapkan. Pencapaian ini lebih tinggi dibandingkan dengan tahun 2018 yaitu naik sekitar $10,70 \%$.

3. Pada tahun 2017 actual expense terserap sebesar 75,56\% dari expense budget yang ditetapkan. Hal ini disebabkan biaya-biaya besar belum dikeluarkan seperti biaya pemeliharaan (maintenance). Pada tahun 2018 actual expense terserap sebesar 99,71 $\%$ dari expense budget. Hal ini menunjukkan penggunaan anggaran lebih optimal.

4. Pencapaian GOP (Gross Operating Profit) di VSSB tergolong dalam low budget (dibawah 40\%). Pada tahun 2015 MK GOP rata-rata sebesar $27,44 \%$ dari penetapan anggaran GOP adalah 40,10\%. Pada tahun 2016, GOP mencapai 26,78\% dari anggaran GOP 40,97\%.

5. VSSB dapat menggunakan analisis CVP dan BEP untuk menentukan perencanaan, pengendalian dan pengambilan keputusan manajemen dengan anggaran yang ditetapkan. 


\section{Saran}

Anggaran sebagai alat perencanaan, pengendalian dan pegambilan keputusan sebaiknya di manfaatkan secara optimal. Dengan memaatuhi target revenue yang telah ditetapkan dan melakukan evaluasi secara menyeluruh dari berbagai pusat pertanggungjawaban. Perlu dilakukan penelitian secara kontinyu dari hasil kinerja berdasarkan budget, untuk mengetahui kelemahan dan kekuatan dari perusahaan.

\section{DAFTAR PUSTAKA}

Anthony dan Govindarajan. 2011. Management Control System: Sistem Pengendalian Manajemen. Buku Dua. Terjemahan Kurniawan Cakrawala, Jakarta: Salemba Empat

Cooper dan Schindler. 2006. Metode Riset Bisnis. Edisi 9. PT Media Global Edukasi

De Porter, Bobbi dan Hernacki, Mike. 1992. Quantum Learning. Membiasakan Belajar Nyaman dan Menyenangkan. Terjemahan oleh Alwiyah Abdurrahman. Bandung: Penerbit Kaifa.

\section{Divie. Analisa Cost-Volume-Profit}

Hansen, D.R. dan Mowen, M. 1999. Management Accounting. Terjemahan Dewi Fitriasari. Penerbit Salemba Empat, Jakarta.

Maylisa dan Budi, 2013, Evaluasi Keputusan Pemberian Potongan Tarif Sewa Kamar (Studi Kasus Pada Hotel Jentra Dagen Yogyakarta). Yogyakarta.
Miles, Matthew B. 1984. Qualitative data analysis: a methods sourcebook / Matthew B. Miles, A. Michael Huberman. Johnny Saldaña. Arizona State University. - Third edition.

Nafarin, M. 2004. Penganggaran Perusahaan, Edisi Revisi. Salemba Empat. Jakarta

Sugiyono. 2010. Metode Penelitian Kuantitatif Kualitatif dan $R \& D$. Penerbit Alfabeta. Bandung

Sujimat, D. Agus. 2000. Penulisan karya ilmiah. Makalah disampaikan pada pelatihan penelitian bagi guru SLTP Negeri di Kabupaten Sidoarjo tanggal 19 Oktober 2000 (Tidak diterbitkan). MKKS SLTP Negeri Kabupaten Sidoarjo

Suparno. 2000. Langkah-langkah Penulisan Artikel Ilmiah dalam Saukah, Ali dan Waseso, M.G. 2000. Menulis Artikel untuk Jurnal Ilmiah. Malang: UM Press.

Supriyono. 1989. Akuntansi Manajemen: Proses Pengendalian Manajemen. BPFE. Yogyakarta

Wahab, Abdul dan Lestari, Lies Amin. 1999. Menulis Karya Ilmiah. Surabaya: Airlangga University Press.

Winardi, Gunawan. 2002. Panduan Mempersiapkan Tulisan Ilmiah. Bandung: Akatiga. 